\title{
The Assessment of the Key Competences for Lifelong Learning-The Fuzzy Model Approach for Sustainable Education
}

\author{
Aleksandar Aleksić ${ }^{1}$, Snežana Nestić ${ }^{1, *(\mathbb{D}}$, Michael Huber $^{1}{ }^{(0)}$ and Nikolina Ljepava ${ }^{2}(\mathbb{D}$ \\ 1 Faculty of Engineering, University of Kragujevac, 34000 Kragujevac, Serbia; aaleksic@kg.ac.rs (A.A.); \\ michael.huber@kg.ac.rs (M.H.) \\ 2 College of Business Administration, American University in the Emirates, Dubai International Academic City \\ Dubai P.O. Box 503000, United Arab Emirates; nikolina.ljepava@aue.ae \\ * Correspondence: s.nestic@kg.ac.rs
}

check for

updates

Citation: Aleksić, A.; Nestić, S.;

Huber, M.; Ljepava, N. The Assessment of the Key Competences for Lifelong Learning-The Fuzzy Model Approach for Sustainable Education. Sustainability 2022, 14, 2686. https://doi.org/10.3390/ su14052686

Academic Editors: Nnamdi O. Madichie and Paul Agu Igwe

Received: 7 February 2022

Accepted: 23 February 2022

Published: 25 February 2022

Publisher's Note: MDPI stays neutral with regard to jurisdictional claims in published maps and institutional affiliations.

Copyright: (C) 2022 by the authors. Licensee MDPI, Basel, Switzerland. This article is an open access article distributed under the terms and conditions of the Creative Commons Attribution (CC BY) license (https:// creativecommons.org/licenses/by/ $4.0 /)$.

\begin{abstract}
Contemporary education in higher education institutions has a goal to provide necessary competences determined by legislative demands, science trends and job market needs to graduated students intending to strengthen their employability. The main idea of this research is to assess the level of students' competences for lifelong learning (LLL). Since it is a very complex task, it is characterized by a lack of information and the vagueness of the inherently subjective nature of human thinking. The uncertain values of the assessed level of students' competences for LLL are represented by linguistic expressions which are modeled by the interval type 2 trapezoidal fuzzy numbers. Ranking of the level of students' competences for LLL is stated as a fuzzy multi-criteria optimization task. The aggregation of students' opinions into unique marks is given by using the proposed fuzzy Delphi technique. The rank of students' competences for LLL is given by using the proposed fuzzy Simple Additive Weighting (FSAW). The order of measures that should be delivered to improve students' competences is based on the obtained rank. The model is tested and discussed on the real data collected from a significant sample of the students with a proposal of future directions of the research.
\end{abstract}

Keywords: competences management; lifelong learning; employability of future engineers; fuzzy Delphi; fuzzy SAW

\section{Introduction}

In industry, almost all companies are struggling to document, maintain and further develop the relevant knowledge and the resulting competencies in the long term. It is suggested that the competencies cannot be taught but can only be built up in a self-organized way while mastering real challenges. Knowledge in the narrower sense does not require competencies. At the same time, the global market significantly impacts the development and enhancement of current study programs all over the world. The global change and unpredicted events might speed up the need for change and improvement of education [1]. To enhance students' achievement, teachers could improve their communication skills and knowledge transfer [2]. At the same time, there is a recognized need for the improvement of formal education and lifelong learning programs [3]. The motivation for this research comes from the fact that ongoing courses at the level of study programs should be improved so they could address emerging employers' needs and enable sustainable education. Continuous improvement is well established in business organizations since they need to monitor market needs and changes. Simultaneously, the courses' enhancement should be very actively practiced at universities since they provide new staff, knowledge, and technology transfer for business companies. If this approach is well designed and practiced, it should enable cultural change [4], improvement, and long-term sustainability [5].

Amongst all challenges in higher education, analysis of students' competences seems to be a very important issue at many universities. The scientific goal of our research is 
to propose a new methodology for assessing and ranking the competences in uncertain environments. The existence of uncertainties is related to competencies since those cannot be taught, they can be built up while mastering real challenges. The utilitarian goal of this research is to determine the lowest-ranked competences of students for lifelong learning (LLL) in compliance with the European reference framework so the weakest competences could be enhanced. It can be assumed that the first step of competences enhancement starts with its assessment [6]. Formally, the enhancement should be induced through the change of the course curricula, so teachers could transfer appropriate knowledge which should result in competence enhancement. In the scope of the proposed methodology, the first activity of the quality improvement related to any variable is measurement or assessment [7]. This activity may be conducted by using crisp values wherever is suitable. In a variety of cases, it cannot be applied since some variables, such as the performances of an education system are not easy to quantify. In compliance with this, different approaches have emerged. Vague values can be well represented by natural language words [8] that represent a linguistic variable. The development of some areas of mathematics, such as the theory of fuzzy sets $[9,10]$, have allowed the linguistic variables to be quantitatively represented in a sufficiently good manner. The concept of type 2 fuzzy sets (T2FSs) was introduced by [8]. Operations associated with T2FSs are very complex [11] and they require enormous computational effort so that there are not many practical applications in modeling linguistic variables. The computational effort with interval type 2 fuzzy numbers (IT2FNs) is reduced and their use is increased to solve different decision-making problems [12]. In recent years, some scholars have suggested using IT2FNs for modeling uncertainties $[13,14]$, so the interval type 2 trapezoidal fuzzy numbers (IT2TrFNs) are chosen to be adequate for the proposed research.

The methodology for the course improvement is recognized at the level of the Ministry of Education, Science, and Technological Development in Serbia but there is no explicit procedure or guideline on how to execute it. So, the research problem is to define the part of this complex procedure related to the identification of the lowest-ranked competences so they could be enhanced through university courses improvement and learning outcomes. The European reference framework indicates the relationship between competences and learning outcomes. The proposed methodology is tested at the engineering bachelor-level study program at the University of Kragujevac.

In the scope of the proposed research, there are several assumptions. The ranking of students' competences for LLL can be adequately stated as a fuzzy multi-criteria optimization task. Students express their assessment of competences for LLL while using predefined linguistic expressions more smoothly compared to the employment of precise numbers. By combining the fuzzy Delphi technique and Fuzzy Simple Additive Weighting (FSAW), the rank of students' competences for LLL can be given exactly. Both techniques are analyzed in the following section.

The paper is organized in the following manner. Section 2 presents a literature review. The proposed methodology is presented in Section 3. In Section 4, the proposed model is illustrated with real-life data. Conclusions are presented in Section 5.

\section{Literature Review}

In compliance with the Recommendation of the European Parliament and the Council on key competences for lifelong learning, "the key competences are those which all individuals need for personal fulfillment and development, active citizenship, social inclusion, and employment" [15].

It is worth mentioning that there are different methodologies to rank the knowledge and competences of students while they perform the assessment [16]. While designing the knowledge and competence assessment, different approaches, such as concept map and game theory could be employed [17]. In the scope of our research, assessing the values of students' competences for LLL is stated as a fuzzy group decision-making problem that follows research trends in other areas [18]. 
As the proposed method consists of fuzzy Delphi and FSAW, the named techniques should be explained in more detail. The Delphi method could be classified as a method of forecasting development based on the opinions of experts in a particular field [19], so it is adjustable to a variety of domains. Simple Additive Weighting (SAW) is a very commonly used technique embracing a weighted summation. The idea is to conduct a weighted summation of rating the performance of each considered feasible alternative [20]. The highest score indicates the best alternative. The existing literature suggests that conventional methods could be extended with an application of fuzzy sets theory. The rest of the explanation presents a relevant literature review which is arranged in two parts: (i) fuzzy Delphi technique and (ii) FSAW.

\subsection{The Fuzzy Delphi Technique}

Research manuscripts reporting large datasets that are deposited in a publicly available database should specify where the data have been deposited and provide the relevant accession numbers. If the accession numbers have not yet been obtained at the time of submission, please state that they will be provided during review. They must be provided prior to publication.

Aggregation of individual opinions into unique assessment may be delivered through the application by using the most popular qualitative techniques [21]. Delphi technique aims to provide the forecast through achieving a group consensus by a group of qualified experts [22]. This method is based on the following assumptions: (i) experts who participate in the assessment of competence values do not meet through the process of assessment,

(ii) they deliver their assessment in soft copy to reduce the time needed for data collection, (iii) the assessment of the competence values is delivered through the several rounds so the responses are collected, and analytical results are given back to experts to start the next round. When the consensus is achieved, based on the average of the final round, the competences are screened [23].

Some scholars suggest the extension of the Delphi technique with: (i) type-1 fuzzy sets [24-27], and (ii) type 2 fuzzy numbers [28]. Aggregation of experts' opinions may be delivered by applying the fuzzy averaging operator [27], the proposed model [24,25], and the fuzzy geometric operator [28]. Some scholars assume that the application of fuzzy geometric operator [29] provides a good base for the preservation of positive features of fuzzy numbers so it is used in this research.

Aggregated opinion in each round is transformed into the representative scalar by using: (i) moment of area [30], and (ii) the proposed procedure [25]. If the scalar value is greater than or equal to the threshold, many scholars suggest that the consensus has been reached $[25,30]$. In our research, the calculation of the distance between each opinion of the decision-maker and aggregated value of an opinion is performed by applying Euclidean distance [27]. It may be considered that the consensus is reached if the value of the distance is acceptable. It may be considered that if the value of the distance is less than 0.2 [27], the consensus is reached [31]. The determination of reaching consensus in each round can be solved by employing the technique of analysis of variance, as a parametric statistical test [28].

In practice, it is assumed that the final solution is obtained in the second round, as in this research.

\subsection{Fuzzy Simple Additive Weighting (FSAW)}

The ranking problems in different research areas may be successfully addressed by the deployment of SAW [32-34]. It is worth mentioning that criteria used for alternatives' assessment can be either cost or benefit nature, so their desired values are supposed to be lowest or highest in treated problems. The fundamental difference between these two criteria is suggested by [35]. Therefore, it is necessary to construct a normalized decision matrix so the values of the criteria could be comparable. In conventional SAW, weighted normalized aggregated value is calculated as the sum of weighted normalized criteria 
values [36]. The rank of alternatives is based on the previously determined values. At the first place, and the last place, the alternative with the adjoined highest, and the lowest, weighted normalized aggregated value, respectively.

It may be considered that the literature covers a variety of papers containing the extension with fuzzy sets theory. The relevant papers are analyzed in Table 1.

Table 1. FSAW extension analysis.

\begin{tabular}{|c|c|c|c|c|}
\hline $\begin{array}{ll}\text { The Author } & \text { The Criteria } \\
\end{array}$ & $\begin{array}{l}\text { The Type of Uncer- } \\
\text { tainty/Granularity/Domain }\end{array}$ & Normalization & Defuzzification/Rank & The Domain of the Application \\
\hline Sagar et al., (2013) [37] & TFNs $/ 7 /(0-1)$ & - & $\begin{array}{l}\text { Defuzzification procedure } \\
\text { [10]/comparison crisp values }\end{array}$ & $\begin{array}{c}\text { The selection of maintenance } \\
\text { strategy of material } \\
\text { handling equipment }\end{array}$ \\
\hline Wang, (2015) [32] & TFNs $/ 5 /(0-1)$ & - & $\begin{array}{l}\text { Defuzzification procedure } \\
\text { [38]/comparison crisp values }\end{array}$ & The selection of location \\
\hline Roszkowska \& Kacprzak, (2016) [39] & TFNs/6/(1-6) & $\begin{array}{l}\text { Linear normalization } \\
\text { procedure [40] }\end{array}$ & Defuzzification procedure [39] & Illustrative examples \\
\hline Muslihudin et al., (2018) [35] & TFNs $/ 5 /(0-1)$ & $\begin{array}{l}\text { Normalization } \\
\text { procedure [36] }\end{array}$ & -/comparison crisp values & Rural Road Development \\
\hline Komatina et al., (2021) [28] & IT2TFNs/7/(1-9) & - & $\begin{array}{l}\text { Defuzzification procedure } \\
\text { [41]/comparison crisp values }\end{array}$ & Enhancement workplace safety \\
\hline The proposed model & IT2TrFNs/5/(1-9) & - & $\begin{array}{l}\text { Comparison of type } 2 \text { fuzzy } \\
\text { numbers method } \\
\text { [24]/comparison crisp values }\end{array}$ & $\begin{array}{l}\text { Ranking of students' } \\
\text { competences for lifelong learning }\end{array}$ \\
\hline
\end{tabular}

Analysis of the papers in Table 1 indicates papers where the SAW method is extended with triangular fuzzy numbers (TFNs) and IT2FNs. [28] suggest integration of SAW and IT2TFNs, but as it assumed in practice, IT2TrFNs embrace uncertainty more comprehensively, so those are applied in our research. The granularity and application domains are different since they are dependent on the size and type of the problem as well as the decision-makers.

It is interesting to denote that a certain number of the authors $[32,35,37]$ do not apply normalization procedures as is suggested by the conventional SAW. This represents the significant difference between the conventional SAW and the proposed SAW that is extended with IT2TrFNs (IT2FSAW). Some authors [32,35,37] defined the domain of the fuzzy numbers on the interval [0-1] so it might be assumed that the normalization is not necessary to be delivered. The domains of the fuzzy numbers can be defined on the scale of measures (1-6) as presented in previously executed research [39]. By analogy to conventional SAW, [39] have applied a linear normalization procedure [40]. Our research supports the application of IT2TFNs on the common measurement scale as in previously delivered research [28]. These crisp values stand for the representative scalars of the fuzzy numbers.

In our research, the elements of the fuzzy decision matrix present assessed values of students' competences for LLL. These values are given by the decision-makers, in this case, students, and they are modeled by IT2TrFNs. Aggregating their assessments into a unique assessment of the level of their competences for LLL is based on the proposed Delphi technique extended with IT2TrFNs (IT2FDelphi). It is worth mentioning that the Delphi technique itself may be considered as a valuable tool in the field of education management [42]. As decision-makers (DMs), in this case, students, have equal importance amongst each other, the total weighted values of each student's competence for LLL are calculated by using a fuzzy geometric mean. The rank of students' competences for LLL is given by applying the method for comparison two IT2TrFNs [24].

\section{Methodology}

This section is supplied with the proposed methodology embracing the IT2FDelphi and IT2FSAW (Figure 1). The rank of competence is given by using the method for comparison of type 2 fuzzy numbers [24]. 


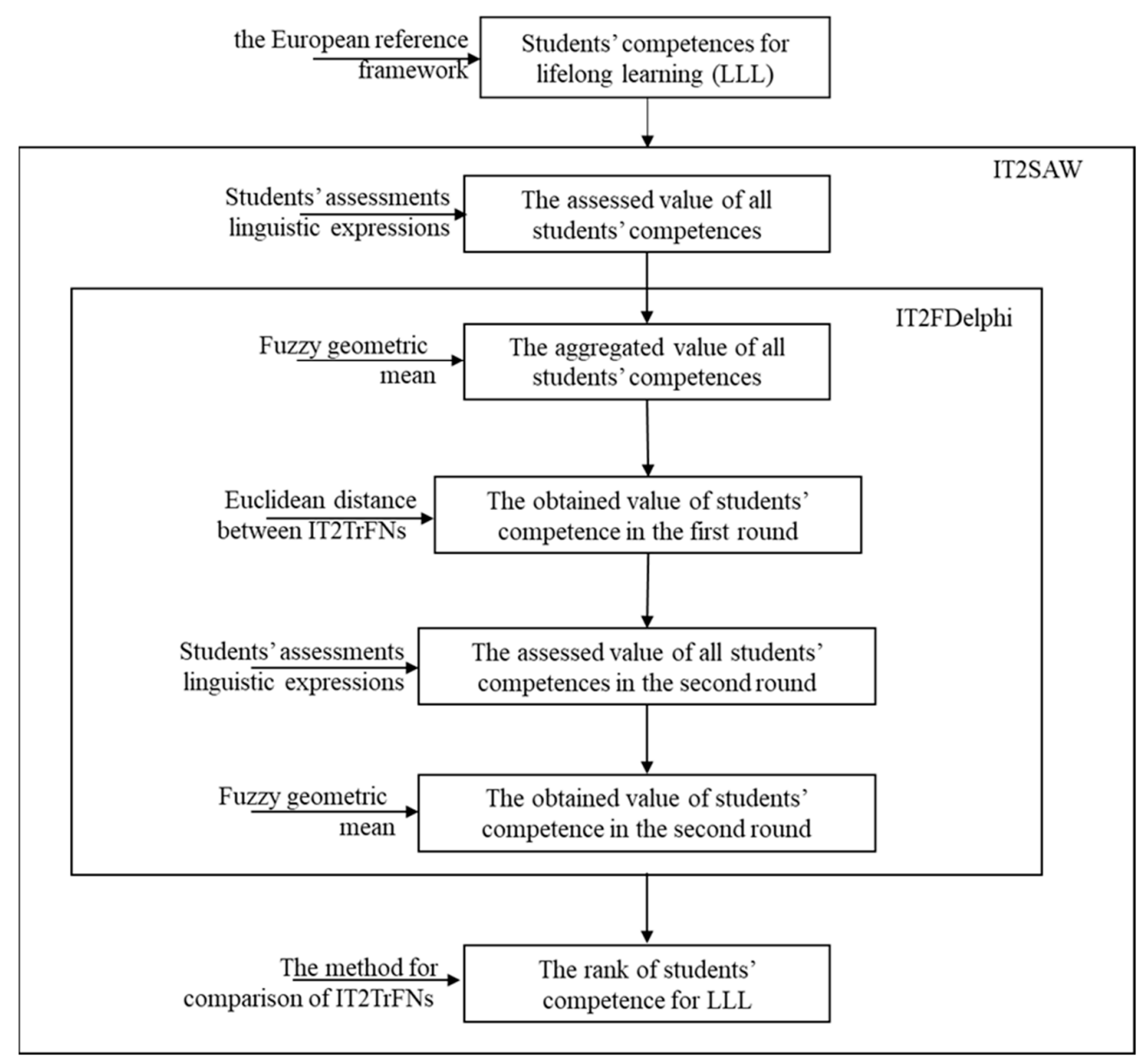

Figure 1. The proposed methodology.

The proposed methodology is supposed to be applied every school year at the beginning and the end of the course delivery so teachers could make statistical analyses and monitor the trend of the assessed competences over years. Based on the obtained rank, the suitable measures for the improvement of the level of students' competences for LLL may be defined. Also, it is essential to provide feedback to the students so they could actively work on the competence's improvement.

\subsection{Defining the Finite Set of the Competences for $L L L$}

The students' competences for LLL are defined according to the European reference framework.

The number of competences according to which the level of students' competences for LLL is assessed is marked as $k=\{1, \ldots, k, \ldots, K\}$.

In this research, the level of students' competences for LLL is presented through eight competences that are defined by A European Reference Framework Key Competences for Lifelong Learning. The denoted competences are:

$(k=1)$ Communication in the mother tongue (the ability to express and interpretation of thoughts, concepts, emotions, and facts in written and/or narrative form encompassing different circumstances), $(k=2)$ Communication in a foreign language, $(k=3)$ Mathematical literacy and basic competencies in science and technology, $(k=4)$ Digital competences, $(k=5)$ Learn how to learn, $(k=6)$ Interpersonal, social and civic competences, $(k=7)$ Taking initiative and entrepreneurship (this competence implies ability and readiness to accept others, i.e., create their innovations), $(k=8)$ Cultural awareness and expression. 


\subsection{Defining the Finite Set of the Decision-Makers}

All students participating in the research are first-year students, so it is worth mentioning that the proposed model is tested on the Engineering Management study program at the University of Kragujevac. They can be formally represented by a set of indexes $i=\{1, \ldots, i, \ldots, I\}$, where I is the total number of students in the treated sample. Index of the student is denoted as $i=1 \ldots, I$.

\subsection{The Selection of the Appropriate Linguistic Expressions for the Competence Description}

In the literature, there are no rules or recommendations on how to determine the granulation of fuzzy numbers that describe uncertainty. Many authors use three [14], five [43], or seven [44] linguistic expressions to describe different types of uncertainties. It can be said that determining the number of linguistic variables depends on the size of the problem and the planner (perhaps called managers) of the experiment.

In this research, five linguistic variables are defined and modeled by IT2TrFNs,

$$
\widetilde{\widetilde{Q}}_{j}=\left(\left(a_{1 j}^{U}, a_{2 j}^{U}, a_{3 j}^{U}, a_{4 j}^{U} ; \mu\left(a_{2 j}^{U}\right), \mu\left(a_{3 j}^{U}\right)\right),\left(a_{1 j}^{L}, a_{2 j}^{L}, a_{3 j}^{L}, a_{4 j}^{L} ; \mu\left(a_{2 j}^{L}\right), \mu\left(a_{3 j}^{L}\right)\right)\right)
$$

where:

$a_{1 j}^{U}$ and $a_{1 j}^{L}$ represent the lowest upper and lower value in the domain,

$a_{2 j}^{U}, a_{3 j}^{U}$ and $a_{2 j}^{L}, a_{3 j}^{L}$ represent the modal upper and modal lower value in the domain,

$a_{4 j}^{U}$ and $a_{4 j}^{L}$ represent the highest upper and lower value in the domain,

$\mu\left(a_{2 j}^{U}\right), \mu\left(a_{3 j}^{U}\right)$ represent the upper membership function,

$\mu\left(a_{2 j}^{L}\right), \mu\left(a_{3 j}^{L}\right)$ represent the lower membership function,

and presented in follows:

very low competence $\left(Q_{1}\right)-((1,1,2,3.5 ; 1,1),(1,1,2,3 ; 0.75,0.75))$

low competence $\left(Q_{2}\right)-((1,2.5,3.5,5 ; 1,1),(1.5,2.5,3.5,4.5 ; 0.75,0.75))$

medium competence $\left(Q_{3}\right)-((3,4.5,5.5,7 ; 1,1),(3.5,4.5,5.5,6.5 ; 0.75,0.75))$

high competence $\left(Q_{4}\right)-((5,6.5,7.5,9 ; 1,1),(5.5,6.5,7.5,8.5 ; 0.75,0.75))$

very high competence $\left(Q_{5}\right)-((6.5,8,9,9 ; 1,1),(7,8,9,9 ; 0.75,0.75))$

The domain values of these IT2TrFNs can be defined at different intervals. There are no specific guidelines on how to define the measurement scales. Value 1, i.e., the value of 5 , denotes that the level of competences for LLL of the student $i, i=1, \ldots, I$ under competence $k, k=1, \ldots, K$ is almost negligible, or very high, respectively.

\subsection{The Proposed Algorithm Combining the Fuzzy Delphi Technique and FSAW}

The problem of assessing the values of students' competences for LLL as well as determining the priority of competences is considered with a goal of continuous curriculum improvement [45]. Determining the priority of the level of students' competences for LLL is based on IT2FSAW. The value of competences by respecting the total number of respondents (in our case students) is calculated by applying IT2FDelphi (Step 2 to Step 6 of the proposed algorithm).

The proposed algorithm can be realized in the following steps.

Step 1. During the first round, the fuzzy rating of the students' competence $i, i=1, \ldots, I$ under competence $k, k=1, \ldots, K$ at considered period, $\widetilde{\vartheta_{k}^{I}}$ is given.

Step 2. Here, the aggregated value of all students' assessment under competence $k, k=1, \ldots, K, \widetilde{\widetilde{\vartheta}_{k}^{I}}$ is obtained by using the fuzzy averaging operator, so that: 


$$
\widetilde{\widetilde{\vartheta}_{k}^{I}}=\sqrt[I]{\prod_{i=1, \ldots, I} \widetilde{\widetilde{V}}_{k i}}=\left(\begin{array}{c}
\left(\sqrt[I]{\prod_{i=1 \ldots, I} a_{1 i^{U}}^{U}} \sqrt[I]{\prod_{i=1 \ldots, I} a_{2 i}^{U}} \sqrt[I]{\prod_{i=1 \ldots, I} a_{3 i^{\prime}}^{U}} \sqrt[I]{\prod_{i=1 \ldots, I} a_{4 i}^{U}} ; 1,1\right), \\
\left(\left(\sqrt[I]{\prod_{i=1 \ldots, I} a_{1 i^{\prime}}^{L}} \sqrt[I]{\prod_{i=1 \ldots, I} a_{2 i^{\prime}}^{L}} \sqrt[I]{\prod_{i=1 \ldots, I} a_{3 i^{\prime}}^{L}} \sqrt[I]{\prod_{i=1 \ldots, I} a_{4 i^{\prime}}^{L}}, 0.75,0.75\right)\right)
\end{array}\right)
$$

Step 3. Determine the Euclidean distance between $\widetilde{\widetilde{\vartheta}}_{k}^{I}$ and $\widetilde{\widetilde{Q}}_{j}[46]$ which is denoted as $d_{k j}, k=1, \ldots, I ; j=1, \ldots, 5$ :

$$
d_{k j}=\sqrt{\frac{1}{8} \cdot\left[\sum_{m=1}^{4}\left(a_{m k}^{U}-a_{m j}^{U}\right)^{2}+\sum_{m=1}^{4}\left(a_{m k}^{L}-a_{m j}^{L}\right)^{2}\right]}
$$

Step 4. Let us determine the value of distance $d_{k}^{*}$ :

$$
d_{k}^{*}=\min _{j=1, \ldots, 5} d_{k j}
$$

Step 5. It may be assumed that the aggregated value of competence $k, k=1, \ldots, K$ in the first round is denoted by the linguistic expression which can be associated with the lowest distance value $d_{k}^{*}$. This information is sent to each student in the research.

Step 6 . In the second round, students are delivering the assessment of the level of their competences for LLL for each competence $k, k=1, \ldots, K$ with respect to $d_{k}^{*}, k=1, \ldots, K$. Let their assessment be denoted as $\widetilde{\widetilde{\vartheta}}_{k}^{I I}, i=1, \ldots, I$.

Step 7. The aggregation of students' assessment in the second round is performed by the fuzzy geometric operator (see Step 2). The aggregated value of the level of students' competences for LLL $k, k=1, \ldots, K$ is denoted as $\widetilde{\widetilde{\vartheta}}_{k} I I=\widetilde{\widetilde{\vartheta}}_{k}$.

Step 8 . The rank of competence for LLL is given by using the method for comparison of IT2TrFNs [24] which is based on the procedure developed by [47].

Step 9. According to the obtained results, management measures could be defined that lead to an increase in student competence.

After applying the proposed algorithm, there should be a review of the measures for effectiveness. All assessments are supposed to be delivered at the beginning and the end of each school year, as it is mentioned before.

\section{The Case Study}

The strengthening of the students' competences for LLL is supposed to be achieved through mastering teaching materials and exercises. The main idea is to assess analyzed competencies so the lowest in the rank could be enhanced.

The research was conducted on a homogeneous sample of 94 students of the first year who have a formal secondary vocational education. The input data is obtained during the period of classes delivery at the Faculty of Engineering, University of Kragujevac. The gender distribution of the students who participated in research is equal. Before participating in the study, students were thoroughly informed about the scope of the study, response options, and the method of providing answers. The students have received an appropriate survey with explanations based on A European Reference Framework Key Competences for Lifelong Learning. As the research was conducted during the classes' delivery, students were provided training on how to assess their competences. The students have filled out the soft copy of the survey during one school class. Each soft copy of the survey was submitted by using the Moodle portal at the University of Kragujevac. It is worth mentioning that the sample of 94 students is representative of a given academic community. 
Fuzzy rating of the level of students' competences for LLL $k, k=1, \ldots, K$ at the level of each student $I, i=1 \ldots, I$ is performed and presented in Appendix A (see Step 1).

Aggregation by using fuzzy geometric mean is illustrated by example (see Step 2):

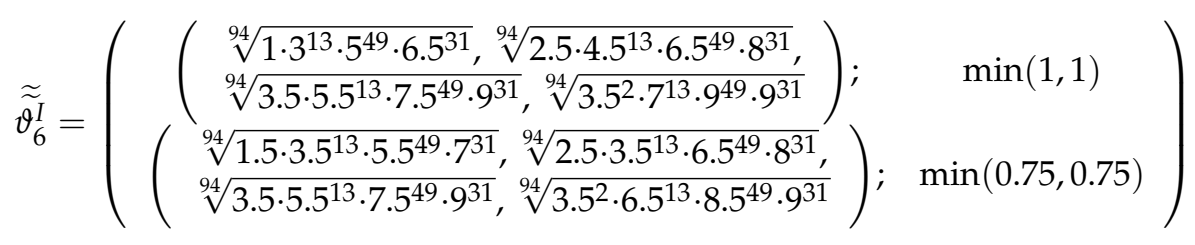

And

$$
\widetilde{\widetilde{\vartheta}_{6}^{I}}=((4.99,6.55,7.57,8.65 ; 1,1),(5.52,6.55,7.57,8.65 ; 0.75,0.75))
$$

The aggregated value of the rest of students' assessment is determined similarly. The distance between $\widetilde{\widetilde{\vartheta}} \frac{}{6}$ and pre-defined linguistic expressions $\widetilde{\widetilde{Q}}_{j}$ is calculated by using Euclidean distance (see Step 3). It is illustrated in the following example:

$$
d_{61}=\sqrt{\frac{1}{8} \cdot\left[\begin{array}{c}
(1-4.99)^{2}+(1-6.55)^{2}+(2-7.57)^{2}+(3.5-4.99)^{2}+(1-8.65)^{2}+ \\
(1-5.52)^{2}+(1-6.55)^{2}+(2-7.57)^{2}+(3-8.29)^{2}
\end{array}\right]}=5.226
$$

Similarly, the distances $\widetilde{\widetilde{\vartheta}} \frac{\text { I }}{6}$ have been calculated by using other predefined linguistic expressions. According to Step 4, the pre-defined linguistic expression, which describes the aggregated value of the level of students' competences for LLL in the most precise manner, is determined. $(k=6)$ :

The proposed procedure is illustrated at the example of students' competence for LLL

$$
d_{6}^{*}=\min _{j=1, \ldots, 5}(5.226 ; 3.865 ; 2.011 ; 0.142 ; 1.281)=0.142
$$

Based on the obtained results, the students are supplied with information that the aggregated level of their competence for LLL $(k=6)$ obtained in the first iteration might be represented by linguistic expression high competence which is modeled by IT2TrFN, $\widetilde{\widetilde{Q}}_{4}$. Also, while assessing this competence for LLL, it should be considered that its value might be represented by linguistic expression very high competence which is modeled by IT2TrFN, $\widetilde{\widetilde{Q}}_{5}$.

The information that is sent to all participating students (see Step 5) regarding the aggregated values of their assessment in the first round is presented in Table 2:

Table 2. The information that is sent to all participating students.

\begin{tabular}{cc}
\hline Competences for LLL & The Information Which Is Sent for Round 2 of the Fuzzy Delphi Technique \\
$(k=1)$ & $\begin{array}{r}\text { might be represented by the linguistic expression high competence }\left(\widetilde{\widetilde{Q}}_{4}\right) \text { in the best manner } \\
\text { might be represented by the linguistic expression high competence }\left(\widetilde{\widetilde{Q}}_{4}\right) \text { in the best manner, but the same } \\
\text { competence might be represented by the linguistic expression medium competence }\left(\widetilde{\widetilde{Q}}_{3}\right) \text {, also. } \\
\text { might be represented by the linguistic expression high competence }\left(\widetilde{\widetilde{Q}}_{4}\right) \text { in the best manner, but the same } \\
\text { competence might be represented by the linguistic expression very high competence }\left(\widetilde{\widetilde{Q}}_{5}\right) \text {, also. } \\
\text { might be represented by the linguistic expression high competence }\left(\widetilde{\widetilde{Q}}_{4}\right) \text { in the best manner, but the same } \\
\text { competence might be represented by the two linguistic expressions: very high competence }\left(\widetilde{\widetilde{Q}}_{5}\right) \text { and medium } \\
\text { competence }\left(\widetilde{\widetilde{Q}}_{3}\right) \text {, also. } \\
\text { might be represented by the linguistic expression medium competence }\left(\widetilde{\widetilde{Q}}_{3}\right) \text { in the best manner, but the same } \\
\text { competence might be represented by the linguistic expression high competence }\left(\widetilde{\widetilde{Q}}_{4}\right) \text {, also. }\end{array}$ \\
\hline
\end{tabular}


The students' assessments are obtained in the second round (see Step 6), also.

The aggregated fuzzy values of the level of students' competences for LLL (see Step 7) are presented in Table 3.

Table 3. The aggregated fuzzy values of the level of students' competences for LLL.

$$
\begin{aligned}
& \widetilde{\widetilde{\vartheta}}_{1}=((5.45,6.96,7.96,9 ; 1,1),(5.95,6.96,7.96,8.66 ; 0.75,0.75)) \\
& \widetilde{\widetilde{\vartheta}}_{2}=((4.54,6.07,7.08,8.51 ; 1,1),(5.05,6.07,7.08,8.03 ; 0.75,0.75)) \\
& \widetilde{\widetilde{\vartheta}}_{3}=((5.10,6.22,7.63,8.86 ; 1,1),(5.61,6.67,7.63,8.45 ; 0.75,0.75)) \\
& \widetilde{\widetilde{\vartheta}}_{4}=((5.44,6.96,7.97,8.88 ; 1,1),(5.95,6.96,7.97,8.59 ; 0.75,0.75)) \\
& \widetilde{\widetilde{\vartheta}}_{5}=((3.39,4.23,4.76,5.75 ; 1,1),(3.68,4.23,4.76,5.22 ; 0.75,0.75)) \\
& \widetilde{\widetilde{\vartheta}}_{6}=((5.25,6.76,7.77,8.90 ; 1,1),(5.75,6.76,7.77,8.53 ; 0.75,0.75)) \\
& \widetilde{\widetilde{\vartheta}}_{7}=((3.14,4.77,5.81,7.43 ; 1,1),(3.70,4.77,5.81,6.83 ; 0.75,0.75)) \\
& \widetilde{\widetilde{\vartheta}}_{8}=((6.17,7.68,8.69,8.93 ; 1,1),(6.67,7.68,8.69,8.85 ; 0.75,0.75))
\end{aligned}
$$

The calculation of the level of students competences' rank for LLL is based on the comparison of IT2TrFNs, $\widetilde{\widetilde{v}}_{k}, k=1, \ldots, K$ (see Step 8 ).

The element values of the upper fuzzy preference matrix, $P U$ and the lower fuzzy preference matrix, $P^{L}$ are calculated according to Equation (2) which is illustrated by the following example:

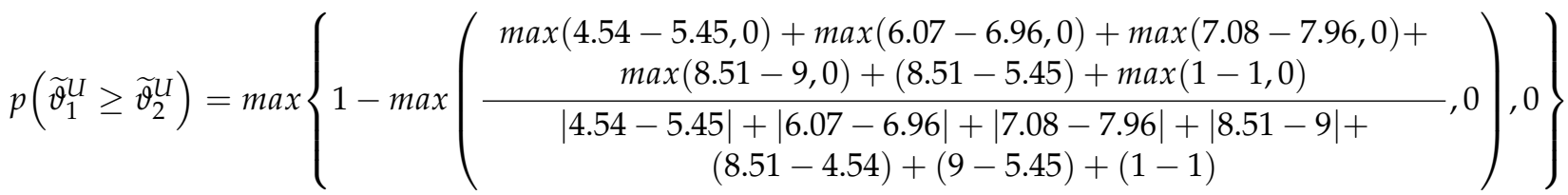

$$
\begin{aligned}
& p\left(\widetilde{\vartheta}_{1}^{U} \geq \widetilde{\vartheta}_{2}^{U}\right) \\
& =\max \{1 \\
& \left.-\max \left(\frac{\max (-0.91,0)+\max (-0.89,0)+\max (-0.88,0)+\max (-0.49,0)+3.06+\max (0,0)}{0.91+0.89+0.88+0.49+3.97+3.55+0}, 0\right), 0\right\} \\
& p\left(\widetilde{\vartheta}_{4}^{U} \geq \widetilde{\vartheta}_{3}^{U}\right)=\max \{1-\max (0.286,0), 0\} \\
& p\left(\widetilde{\vartheta}_{4}^{U} \geq \widetilde{\vartheta}_{3}^{U}\right)=\max \{0.714,0\} \\
& p\left(\widetilde{\vartheta}_{4}^{U} \geq \widetilde{\vartheta}_{3}^{U}\right)=0.714
\end{aligned}
$$

So that:

$$
p\left(\widetilde{\vartheta}_{2}^{U} \geq \widetilde{\vartheta}_{1}^{U}\right)=1-0.714=0.286
$$

The upper fuzzy preference matrix, $P U$ is:

$$
P^{U}=\left[\begin{array}{cccccccc}
0.5 & 0.714 & 0.597 & 0.518 & 0.983 & 0.563 & 0.123 & 0.343 \\
0.286 & 0.5 & 0.350 & 0.293 & 0.916 & 0.323 & 0.783 & 0.195 \\
0.403 & 0.650 & 0.5 & 0.415 & 0.960 & 0.458 & 0.846 & 0.275 \\
0482 & 0.707 & 0.585 & 0.5 & 0.982 & 0.558 & 0.874 & 0.322 \\
0017 & 0.084 & 0.040 & 0.018 & 0.5 & 0.030 & 0.079 & 1 \\
0.437 & 0.677 & 0.542 & 0.442 & 0.970 & 0.5 & 0.859 & 0.297 \\
0.877 & 0217 & 0.154 & 0.126 & 0.921 & 0.141 & 0.5 & 0.073 \\
0.657 & 0.805 & 0.725 & 0.678 & 0 & 0.703 & 0.927 & 0.5
\end{array}\right]
$$


The lower fuzzy preference matrix, $P^{L}$ is:

$$
P^{L}=\left[\begin{array}{cccccccc}
0.5 & 0.769 & 0.631 & 0513 & 1 & 0585 & 0.938 & 0.274 \\
0.231 & 0.5 & 0.306 & 0.235 & 0.987 & 0.273 & 0.841 & 0.126 \\
0.369 & 0.694 & 0.5 & 0377 & 1 & 0.441 & 0.907 & 0.207 \\
0.487 & 0.765 & 0.623 & 0.5 & 1 & 0.576 & 0.938 & 0.265 \\
0 & 0.013 & 0 & 0 & 0.5 & 1 & 0.193 & 1 \\
0.415 & 0.727 & 0.559 & 0.424 & 0 & 0.5 & 0.921 & 0.231 \\
0.062 & 0.159 & 0.093 & 0.062 & 0.807 & 0.079 & 0.5 & 0.010 \\
0.726 & 0.874 & 0.793 & 0.735 & 0 & 0.769 & 0.990 & 0.5
\end{array}\right]
$$

Ranking value is illustrated on the example $(k=1)$ :

$$
\begin{gathered}
\operatorname{Rank}\left(\widetilde{\vartheta}_{1}^{U}\right)=\frac{1}{8 \cdot(8-1)} \cdot\{0.5+0.714+0.597+0.518+0.983+0.563+0.123+0.334+4-1\}=0.131 \\
\operatorname{Rank}\left(\widetilde{\vartheta}_{1}^{L}\right)=\frac{1}{8 \cdot(8-1)} \cdot\{0.5+0.769+0.631+0.513+2+0.585+0.938+0.274+4-1\}=0.147
\end{gathered}
$$

The total ranking value:

$$
\operatorname{Rank}\left(\widetilde{\widetilde{\vartheta}}_{1}\right)=\frac{1}{2} \cdot(0.131+0.147)=0.139
$$

In the same way, are calculated ranking values of the rest of the students' competences for LLL and presented in Table 4.

Table 4. The total ranking values and rank of students' competences for LLL.

\begin{tabular}{ccc}
\hline & $\boldsymbol{R a n k}\left(\widetilde{\widetilde{\vartheta}}_{k}\right)$ & Rank of Competences \\
\hline$k=1$ & 0.139 & 3 \\
$k=2$ & 0.117 & 6 \\
$k=3$ & 0.134 & 4 \\
$k=4$ & 0.144 & 2 \\
$k=5$ & 0.094 & 8 \\
$k=6$ & 0.129 & 5 \\
$k=7$ & 0.096 & 7 \\
$k=8$ & 0.146 & 1 \\
\hline
\end{tabular}

Based on Table 4, it may be concluded that the highest level of competences is denoted under competence $k=8$ (Cultural awareness and expression). The lowest level of the competences is denoted under competence $k=5$ (Learn how to learn). The results seem to be quite logical since students believe that their competence in cultural awareness is at the highest level. Also, students believe that their ability how to learn is at the lowest level. This is worth to be furthermore investigation since 2020 and 2021 were specific years due to distance learning issues caused by the COVID 19 pandemic. The education process dominantly should enhance the lowest ranking competence, so different activities should be defined in achieving this goal.

Taking that into consideration, the improvement of the curricula could be the solution but according to the opinion of authors, an appropriate textbook or auxiliary university textbook with the appropriate content and scope could be a more effective solution. The content should be designed so the lowest-ranked competences could be enhanced by applying theoretical and practical approaches. The textbook should cover, among all, mapping entrepreneurial competencies, fundamentals of marketing, teams and team management, business ethics and social responsibility, market analysis, production costs and income of 
a competing company, encouraging entrepreneurship and innovations, and the courage to embrace new ideas and others. It is worth mentioning that competences for LLL are fundamental for acquiring new knowledge for students that are going to become employees or even entrepreneurs over years. That opens the future directions of the research since the presented survey can be executed in the following semesters and the success of the proposed auxiliary textbook can be examined.

The proposed methodology is interesting to be compared with existing approaches of assessing knowledge where students are conducting the assessment [16]. If papers are compared, it may be concluded that the outcome of the assessment is obtained by applying different mathematical tools. In the course of future research, it would be interesting to compare the outcomes of our methodology with the outcomes obtained with the same input data by applying the methodology used by [16].

\section{Conclusions}

The improvement of courses at different level study programs is a very important issue at universities all over the world. The drivers for change and improvement might be identified in both, the university itself and its environment. The major input comes from the market demands, but also, the development of new technologies, ongoing research, and innovations activities may tailor the need for change and improvement. At the same time, the person in charge of program delivery at faculty/university should be aware of the students' knowledge and competences acquired during the program realization. In compliance with that, some corrective actions might be proposed and implemented.

Since the knowledge level at the denoted course is assessed at the defined scales, their assessment is formal. The authors of this paper have recognized the need for assessing student competences as an answer to the research problem. It is shown that the level of students' competences for LLL can be successfully stated as a fuzzy multi-criteria decisionmaking task. Due to the complexity of competences, it is not easy to present the level of mastering it by precise numbers. In the scope of the research, it is indicated that students have expressed their assessment of competences for LLL while using predefined linguistic expressions more smoothly compared to the employment of precise numbers. The proposed methodology embracing the IT2FDelphi and IT2FSAW is tested on the real data provided by students enrolled in the existing bachelor study program.

The main theoretical contribution of the research is that a new methodology for assessing and ranking the competences in uncertain environments is proposed: (1) the description of assessed competences in presence of uncertainties is presented by IT2TrFNs, (2) the assessed value of the competences is presented as a task of fuzzy group decision making and solved by employing fuzzy Delphi, (3) the rank of the competences is determined by fuzzy SAW technique.

The utilitarian contribution of the research is the determination of the order of LLL competences improvement. The weakest competences should be enhanced firstly through the university course improvement. One of the recommendations of the European Parliament and the Council provides the base for building the key competences for lifelong learning - a European reference framework. In compliance with the obtained results, students should be encouraged to develop the competencies that may serve as a base for the overall enhancement of lifelong learning competences. Those competences are related to identifying opportunities by searching the Internet sources, which should be supported with creativity and ethical and sustainable thinking.

The key message of the research outcome would be setting the guideline that explains the proposed method for competence ranking so teachers could make the assessment every year and monitor the level of students' competences. In this way, a comprehensive statistical analysis could be provided to define new teaching material including new textbooks, case studies, practice books, monographs, etc.

The directions of the future research should be related to the promotion of other competences that should be enhanced at the student level, such as competences related 
to self-awareness and self-efficacy as well as resource management and financial and economic literacy. According to the stated, it is worth mentioning that students should cooperate with other students in the implementation of case studies, seminar work, and the creation of digital content so the competence of work with others should be enhanced, too.

Author Contributions: Conceptualization, A.A. and S.N.; investigation, M.H. and S.N.; methodology, A.A. and N.L., supervision S.N., validation, M.H., S.N., A.A. and N.L.; visualization, M.H., N.L.; writing - original draft, A.A., S.N., N.L. and M.H. All authors have read and agreed to the published version of the manuscript.

Funding: This research received no external funding.

Institutional Review Board Statement: Not applicable.

Informed Consent Statement: Not applicable.

Data Availability Statement: Data is contained within the article.

Conflicts of Interest: The authors declare no conflict of interest.

\section{Appendix A}

Table A1. Input data—Step 1 of the proposed Algorithm.

\begin{tabular}{|c|c|c|c|c|c|c|c|c|c|}
\hline \multicolumn{2}{|c|}{ STUDENT } & $k=1$ & $k=2$ & $k=3$ & $k=4$ & $k=5$ & $k=6$ & $k=7$ & $k=8$ \\
\hline Student & 1 & $\mathrm{Q} 4$ & Q4 & $\mathrm{Q} 4$ & Q4 & Q3 & Q4 & Q3 & Q5 \\
\hline Student & 2 & $\mathrm{Q} 4$ & $\mathrm{Q} 4$ & $\mathrm{Q} 4$ & Q5 & Q4 & Q3 & Q3 & Q3 \\
\hline Student & 3 & $\mathrm{Q} 4$ & $\mathrm{Q} 2$ & Q3 & $\mathrm{Q} 3$ & Q3 & Q5 & $\mathrm{Q} 2$ & Q5 \\
\hline Student & 4 & Q5 & Q5 & $\mathrm{Q} 4$ & Q4 & Q4 & Q5 & Q3 & $\mathrm{Q} 4$ \\
\hline Student & 5 & Q5 & $\mathrm{Q} 4$ & $\mathrm{Q} 4$ & Q3 & Q4 & $\mathrm{Q} 4$ & $\mathrm{Q} 4$ & Q3 \\
\hline Student & 6 & $\widehat{\mathrm{Q}} 4$ & $\widehat{\mathrm{Q}} 4$ & Q5 & Q5 & Q3 & Q5 & Q2 & Q5 \\
\hline Student & 7 & Q3 & Q5 & Q3 & Q3 & Q4 & Q3 & Q3 & Q3 \\
\hline Student & 8 & $\mathrm{Q} 4$ & $\mathrm{Q} 4$ & $\mathrm{Q} 4$ & Q4 & Q3 & Q5 & $\mathrm{Q} 4$ & Q5 \\
\hline Student & 9 & Q5 & $\mathrm{Q} 4$ & $\mathrm{Q} 4$ & Q4 & Q3 & Q4 & Q4 & Q5 \\
\hline Student & 10 & $\mathrm{Q} 4$ & $\mathrm{Q} 4$ & $\mathrm{Q} 4$ & Q3 & Q4 & Q4 & Q4 & $\mathrm{Q} 4$ \\
\hline Student & 11 & Q5 & Q5 & $\widehat{\mathrm{Q}} 4$ & Q5 & Q2 & $\widehat{Q} 4$ & $\mathrm{Q} 1$ & Q5 \\
\hline Student & 12 & Q5 & Q5 & Q5 & Q3 & Q5 & $\widehat{Q} 4$ & $\mathrm{Q} 2$ & Q4 \\
\hline Student & 13 & $\mathrm{Q} 4$ & $\mathrm{Q} 4$ & Q5 & Q5 & Q5 & Q3 & Q3 & Q4 \\
\hline Student & 14 & Q5 & Q4 & $\widehat{\mathrm{Q}} 4$ & $\widehat{Q} 4$ & Q5 & $\widehat{Q} 4$ & Q2 & $\mathrm{Q} 4$ \\
\hline Student & 15 & $\mathrm{Q} 4$ & $\mathrm{Q} 4$ & Q4 & Q5 & Q2 & Q5 & Q2 & Q5 \\
\hline Student & 16 & $\mathrm{Q} 4$ & Q3 & Q5 & Q5 & $\mathrm{Q} 4$ & Q4 & Q5 & Q4 \\
\hline Student & 17 & Q5 & $\mathrm{Q} 4$ & $\mathrm{Q} 4$ & Q4 & Q3 & Q4 & Q3 & Q4 \\
\hline Student & 18 & $\mathrm{Q} 4$ & Q3 & $\mathrm{Q} 4$ & $\mathrm{Q} 4$ & Q3 & Q4 & Q2 & Q5 \\
\hline Student & 19 & Q5 & $\widehat{Q} 4$ & $\widehat{\mathrm{Q}} 4$ & Q4 & $\widehat{Q} 4$ & $\widehat{Q} 4$ & $\widehat{Q} 4$ & $\mathrm{Q} 4$ \\
\hline Student & 20 & Q5 & $\mathrm{Q} 4$ & Q4 & Q4 & Q4 & Q5 & $\mathrm{Q} 2$ & Q3 \\
\hline Student & 21 & Q5 & Q5 & Q5 & Q5 & Q3 & $\mathrm{Q} 4$ & Q3 & Q4 \\
\hline Student & 22 & $\mathrm{Q} 4$ & $\widehat{Q} 4$ & $\widehat{\mathrm{Q}} 4$ & Q5 & Q3 & Q5 & Q2 & $\mathrm{Q} 4$ \\
\hline Student & 23 & Q5 & $\mathrm{Q} 4$ & Q5 & Q5 & Q4 & Q4 & Q3 & Q4 \\
\hline Student & 24 & Q5 & $\mathrm{Q} 4$ & $\widehat{Q} 4$ & Q5 & $\mathrm{Q} 2$ & Q5 & Q5 & Q5 \\
\hline Student & 25 & $\widehat{\mathrm{Q}} 4$ & $\widehat{\mathrm{Q}} 4$ & $\widehat{\mathrm{Q}} 4$ & Q5 & Q5 & $\widehat{Q} 4$ & Q3 & Q3 \\
\hline Student & 26 & $\mathrm{Q} 4$ & Q3 & $\mathrm{Q} 4$ & Q4 & Q3 & $\mathrm{Q} 4$ & Q3 & Q3 \\
\hline Student & 27 & $\mathrm{Q} 4$ & Q3 & Q3 & Q3 & $\mathrm{Q} 4$ & Q4 & $\mathrm{Q} 2$ & Q5 \\
\hline Student & 28 & $\mathrm{Q} 4$ & Q3 & Q4 & Q5 & Q3 & Q5 & Q2 & Q5 \\
\hline Student & 29 & $\mathrm{Q} 4$ & Q3 & $\widetilde{Q} 4$ & Q4 & Q5 & Q4 & $\widehat{Q} 4$ & Q4 \\
\hline Student & 30 & Q5 & Q5 & Q5 & Q5 & Q4 & Q4 & Q3 & $\mathrm{Q} 4$ \\
\hline Student & 31 & Q5 & Q5 & $\mathrm{Q} 4$ & Q5 & Q3 & Q4 & $\mathrm{Q} 1$ & Q5 \\
\hline Student & 32 & Q5 & $\widehat{Q} 4$ & $\widehat{\mathrm{Q}} 4$ & Q5 & $\widehat{Q} 4$ & Q5 & Q3 & Q5 \\
\hline Student & 33 & Q5 & Q3 & Q3 & Q4 & Q4 & Q4 & Q5 & Q5 \\
\hline Student & 34 & $\mathrm{Q} 4$ & Q3 & Q5 & Q5 & Q3 & Q4 & Q2 & Q4 \\
\hline Student & 35 & $\widehat{\mathrm{Q}} 4$ & Q5 & $\widehat{\mathrm{Q}} 4$ & Q5 & Q2 & $\widehat{Q} 4$ & Q2 & Q5 \\
\hline Student & 36 & $\mathrm{Q} 4$ & Q3 & Q4 & Q4 & Q3 & Q4 & Q4 & Q4 \\
\hline
\end{tabular}


Table A1. Cont.

\begin{tabular}{|c|c|c|c|c|c|c|c|c|c|}
\hline \multicolumn{2}{|c|}{ STUDENT } & $k=1$ & $k=2$ & $k=3$ & $k=4$ & $k=5$ & $k=6$ & $k=7$ & $k=8$ \\
\hline Student & 37 & $\mathrm{Q} 4$ & Q4 & Q5 & Q5 & Q2 & Q3 & Q2 & Q2 \\
\hline Student & 38 & $\widehat{\mathrm{Q}} 4$ & $\widehat{\mathrm{Q}} 4$ & $\widehat{\mathrm{Q}} 4$ & Q5 & Q3 & $\widehat{Q} 4$ & Q3 & $\mathrm{Q} 4$ \\
\hline Student & 39 & Q5 & Q4 & Q4 & Q4 & Q5 & Q3 & Q4 & $\widehat{Q} 4$ \\
\hline Student & 40 & Q5 & Q3 & Q5 & Q5 & Q4 & Q5 & $\widetilde{Q} 4$ & Q4 \\
\hline Student & 41 & Q5 & $\widehat{Q} 4$ & $\widehat{\mathrm{Q}} 4$ & $\widehat{Q} 4$ & Q4 & $\widehat{\mathrm{Q}} 4$ & Q3 & Q4 \\
\hline Student & 42 & Q5 & Q4 & Q5 & Q5 & Q3 & Q5 & Q3 & Q5 \\
\hline Student & 43 & Q4 & Q4 & Q4 & Q5 & Q4 & Q3 & Q2 & $\mathrm{Q} 4$ \\
\hline Student & 44 & $\mathrm{Q} 4$ & Q3 & Q5 & Q3 & Q4 & Q4 & Q4 & Q4 \\
\hline Student & 45 & Q5 & Q5 & Q5 & Q4 & Q4 & Q3 & Q4 & Q4 \\
\hline Student & 46 & $\widehat{\mathrm{Q}} 4$ & $\widehat{\mathrm{Q}} 4$ & $\widehat{\mathrm{Q}} 4$ & $\widehat{Q} 4$ & Q4 & $\widehat{Q} 4$ & $\widehat{Q} 4$ & $\mathrm{Q} 4$ \\
\hline Student & 47 & $\mathrm{Q} 4$ & Q3 & Q4 & Q5 & Q3 & Q4 & Q2 & Q5 \\
\hline Student & 48 & Q5 & Q4 & Q5 & Q3 & Q5 & Q4 & Q5 & $\mathrm{Q} 4$ \\
\hline Student & 49 & $\widehat{\mathrm{Q}} 4$ & $\widehat{Q} 4$ & $\widehat{\mathrm{Q}} 4$ & $\widehat{Q} 4$ & Q3 & $\widehat{\mathrm{Q}} 4$ & $\widehat{Q} 4$ & Q4 \\
\hline Student & 50 & $\mathrm{Q} 4$ & Q4 & Q5 & Q4 & Q4 & Q3 & $\mathrm{Q} 2$ & $\mathrm{Q} 4$ \\
\hline Student & 51 & $\mathrm{Q} 4$ & Q2 & $\widehat{\mathrm{Q}} 4$ & $\widehat{Q} 4$ & Q2 & Q3 & Q2 & $\mathrm{Q} 4$ \\
\hline Student & 52 & Q5 & $\mathrm{Q} 4$ & Q5 & Q3 & Q4 & Q5 & Q4 & Q4 \\
\hline Student & 53 & Q4 & Q4 & Q4 & Q5 & Q3 & Q5 & Q3 & Q5 \\
\hline Student & 54 & Q5 & $\widehat{\mathrm{Q}} 4$ & $\widehat{Q} 5$ & $\widehat{Q} 4$ & Q4 & $\widehat{Q} 4$ & Q3 & Q4 \\
\hline Student & 55 & $\mathrm{Q} 4$ & Q3 & Q3 & Q4 & Q4 & Q4 & Q4 & Q4 \\
\hline Student & 56 & Q5 & $\mathrm{Q} 4$ & Q5 & Q4 & Q3 & Q5 & Q3 & $\mathrm{Q} 4$ \\
\hline Student & 57 & Q4 & $\mathrm{Q} 4$ & Q5 & Q4 & Q4 & Q5 & Q3 & Q5 \\
\hline Student & 58 & $\mathrm{Q} 4$ & $\mathrm{Q} 4$ & Q5 & Q5 & Q3 & Q2 & Q2 & Q2 \\
\hline Student & 59 & Q5 & $\widehat{Q} 4$ & $\widehat{\mathrm{Q}} 4$ & $\widehat{Q} 4$ & Q4 & $\widehat{Q} 4$ & Q5 & $\mathrm{Q} 4$ \\
\hline Student & 60 & $\mathrm{Q} 4$ & Q4 & Q4 & Q4 & Q5 & Q5 & Q5 & Q4 \\
\hline Student & 61 & Q5 & $\mathrm{Q} 4$ & $\mathrm{Q} 4$ & Q4 & Q5 & Q5 & Q5 & Q5 \\
\hline Student & 62 & Q5 & Q3 & Q3 & Q2 & Q1 & Q3 & Q3 & Q4 \\
\hline Student & 63 & Q5 & Q5 & Q5 & Q5 & Q4 & Q5 & Q4 & Q5 \\
\hline Student & 64 & Q5 & Q5 & $\widetilde{Q} 4$ & Q5 & Q5 & Q4 & Q4 & $\mathrm{Q} 4$ \\
\hline Student & 65 & Q5 & Q3 & Q3 & Q5 & Q4 & Q5 & $\widehat{Q} 4$ & Q4 \\
\hline Student & 66 & $\mathrm{Q} 4$ & Q4 & Q5 & Q5 & Q4 & Q4 & Q5 & Q5 \\
\hline Student & 67 & $\mathrm{Q} 4$ & Q3 & Q3 & Q4 & Q4 & $\mathrm{Q} 4$ & $\widehat{Q} 4$ & $\mathrm{Q} 4$ \\
\hline Student & 68 & Q5 & Q5 & Q4 & Q5 & Q5 & Q5 & Q4 & Q5 \\
\hline Student & 69 & Q5 & Q3 & Q3 & Q5 & Q4 & Q4 & Q5 & Q4 \\
\hline Student & 70 & Q5 & Q5 & Q5 & Q5 & Q5 & Q5 & Q5 & Q5 \\
\hline Student & 71 & Q5 & Q4 & Q5 & Q5 & Q5 & Q4 & Q4 & Q4 \\
\hline Student & 72 & Q5 & $\widehat{\mathrm{Q}} 4$ & $\widehat{Q} 5$ & Q5 & Q5 & Q5 & $\widehat{Q} 4$ & Q5 \\
\hline Student & 73 & Q5 & Q3 & Q4 & Q5 & Q3 & Q5 & Q3 & Q2 \\
\hline Student & 74 & Q5 & $\mathrm{Q} 2$ & Q5 & Q4 & Q5 & Q3 & $\widehat{Q} 4$ & Q5 \\
\hline Student & 75 & Q5 & $\widehat{\mathrm{Q}} 4$ & Q3 & $\widehat{Q} 4$ & Q3 & Q5 & Q2 & Q5 \\
\hline Student & 76 & Q5 & Q4 & Q3 & Q4 & Q3 & Q4 & Q4 & Q4 \\
\hline Student & 77 & Q5 & Q5 & Q5 & Q5 & Q5 & Q5 & Q5 & Q5 \\
\hline Student & 78 & Q5 & $\widehat{Q} 4$ & $\widehat{\mathrm{Q}} 4$ & $\widehat{\mathrm{Q}} 4$ & Q4 & $\widehat{\mathrm{Q}} 4$ & $\widehat{Q} 5$ & Q5 \\
\hline Student & 79 & $\mathrm{Q} 4$ & Q2 & Q3 & Q3 & Q4 & Q3 & Q3 & $\mathrm{Q} 4$ \\
\hline Student & 80 & $\mathrm{Q} 4$ & Q5 & $\widetilde{Q} 4$ & Q4 & Q4 & Q4 & $\widetilde{Q} 4$ & $\mathrm{Q} 4$ \\
\hline Student & 81 & Q5 & Q4 & Q4 & Q4 & Q4 & Q4 & Q5 & Q5 \\
\hline Student & 82 & Q5 & Q5 & $\mathrm{Q} 4$ & Q5 & Q4 & $\mathrm{Q} 4$ & Q5 & Q5 \\
\hline Student & 83 & Q5 & Q1 & $\widehat{\mathrm{Q}} 4$ & Q3 & Q4 & Q5 & $\widehat{Q} 4$ & Q5 \\
\hline Student & 84 & Q5 & $\mathrm{Q} 4$ & Q5 & Q5 & Q5 & Q4 & Q4 & Q5 \\
\hline Student & 85 & Q5 & Q3 & Q5 & Q5 & Q4 & Q5 & Q4 & $\mathrm{Q} 4$ \\
\hline Student & 86 & Q5 & $\widehat{Q} 4$ & Q3 & Q5 & Q3 & Q3 & Q3 & Q4 \\
\hline Student & 87 & Q5 & Q3 & Q3 & Q5 & Q4 & Q5 & Q4 & Q3 \\
\hline Student & 88 & Q5 & Q3 & $\mathrm{Q} 4$ & Q5 & Q4 & Q5 & Q4 & $\mathrm{Q} 4$ \\
\hline Student & 89 & Q4 & Q2 & Q3 & Q2 & Q3 & Q4 & Q3 & $\mathrm{Q} 4$ \\
\hline Student & 90 & $\mathrm{Q} 4$ & Q3 & Q4 & Q4 & Q5 & Q4 & Q4 & $\mathrm{Q} 4$ \\
\hline Student & 91 & $\widehat{\mathrm{Q}} 4$ & Q2 & Q3 & Q3 & Q4 & $\widehat{Q} 4$ & Q3 & Q4 \\
\hline Student & 92 & Q5 & Q3 & Q4 & Q5 & Q5 & Q5 & $\mathrm{Q} 2$ & Q4 \\
\hline Student & 93 & Q5 & Q4 & $\widetilde{Q} 4$ & Q3 & Q4 & Q4 & Q4 & Q5 \\
\hline Student & 94 & Q5 & Q3 & Q4 & Q4 & Q4 & $\widehat{Q} 4$ & Q4 & Q4 \\
\hline
\end{tabular}




\section{References}

1. Dishon, G.; Gilead, T. Adaptability and Its Discontents: 21st-Century Skills and the Preparation for an Unpredictable Future. Br. J. Educ. Stud. 2021, 69, 393-413. [CrossRef]

2. López, Á.R.; Souto, J.E.; Noblejas, M.L.A. Improving Teaching Capacity to Increase Student Achievement: The Key Role of Communication Competences in Higher Education. Stud. Educ. Eval. 2019, 60, 205-213. [CrossRef]

3. Harris, A.; Jones, M. Leading Educational Change and Improvement at Scale: Some Inconvenient Truths about System Performance. Int. J. Leadersh. Educ. 2017, 20, 632-641. [CrossRef]

4. Unzueta, G.; Esnaola, A.; Eguren, J.A. Continuous Improvement Framework to Develop Cultural Change: Case Study, Capital Goods Company. TQM J. 2020, 32, 1327-1348. [CrossRef]

5. de La Torre, E.M.; Perez-Encinas, A.; Gomez-Mediavilla, G. Fostering Sustainability through Mobility Knowledge, Skills, and Attitudes. Sustainability 2022, 14, 1349. [CrossRef]

6. de la Vega, A.G. A Proposal for Geography Competence Assessment in Geography Fieldtrips for Sustainable Education. Sustainability 2022, 14, 1429. [CrossRef]

7. Gupta, M.; Kaplan, H.C. Measurement for Quality Improvement: Using Data to Drive Change. J. Perinatol. 2020, 40, 962-971. [CrossRef]

8. Zadeh, L.A. The Concept of a Linguistic Variable and Its Application to Approximate Reasoning-I. Inf. Sci. 1975, 8, 199-249. [CrossRef]

9. Zimmermann, H.J. Fuzzy Set Theory. Wiley Interdiscip. Rev. Comput. Stat. 2010, 2, 317-332. [CrossRef]

10. Dubois, D.; Prade, H. Systems of Linear Fuzzy Constraints. Fuzzy Sets Syst. 1980, 3, 37-48. [CrossRef]

11. Mendel, J.M. Uncertain Rule-Based Fuzzy Systems; Springer International Publishing: Cham, Switzerland, 2017. [CrossRef]

12. Celik, E.; Gul, M.; Aydin, N.; Gumus, A.T.; Guneri, A.F. A Comprehensive Review of Multi Criteria Decision Making Approaches Based on Interval Type-2 Fuzzy Sets. Knowl. Based Syst. 2015, 85, 329-341. [CrossRef]

13. Mohamadghasemi, A.; Hadi-Vencheh, A.; Lotfi, F.H.; Khalilzadeh, M. An Integrated Group FWA-ELECTRE III Approach Based on Interval Type-2 Fuzzy Sets for Solving the MCDM Problems Using Limit Distance Mean. Complex Intell. Syst. 2020, 6, 355-389. [CrossRef]

14. Aleksić, A.; Ristić, R.; Komatina, N.; Tadić, D. Advanced Risk Assessment in Reverse Supply Chain Processes: A Case Study in Republic of Serbia. Adv. Prod. Eng. Manag. 2019, 14, 421-434. [CrossRef]

15. Recommendation of the European Parliament and of the Council on Key Competences for Lifelong Learning. Off. J. Eur. Union 2006, 22, 10-18.

16. Gaworski, M.; de Cacheleu, C.; Inghels, C.; Leurs, L.; Mazarguil, C.; Ringot, B.; Tzu-Chen, C. The Topic of the Ideal Dairy Farm Can Inspire How to Assess Knowledge about Dairy Production Processes: A Case Study with Students and Their Contributions. Processes 2021, 9, 1357. [CrossRef]

17. Kumar, R. Formative knowledge assessment through games using concept map and game theory. J. Inf. Knowl. Manag. 2018, 17, 1850030. [CrossRef]

18. Safarzadeh, S.; Khansefid, S.; Rasti-Barzoki, M. A Group Multi-Criteria Decision-Making Based on Best-Worst Method. Comput. Ind. Eng. 2018, 126, 111-121. [CrossRef]

19. Brown, B.B. Delphi Process: A Methodology Used for the Elicitation of Opinions of Experts; Rand Corp: Santa Monica, CA, USA, 1968

20. Kaliszewski, I.; Podkopaev, D. Simple Additive Weighting-A Metamodel for Multiple Criteria Decision Analysis Methods. Expert Syst. Appl. Int. J. 2016, 54, 155-161. [CrossRef]

21. Anderson, D.R.; Sweeney, D.J.; Williams, T.A. Quantitative Methods for Business; South-Western College Pub: Nashville, TN, USA, 1998.

22. Mohamad, S.N.A.; Embi, M.A.; Nordin, N. Determining E-Portfolio Elements in Learning Process Using Fuzzy Delphi Analysis Int. Educ. Stud. 2015, 8, 171-176. [CrossRef]

23. Förster, B.; von der Gracht, H. Assessing Delphi Panel Composition for Strategic Foresight-A Comparison of Panels Based on Company-Internal and External Participants. Technol. Forecast. Soc. Change 2014, 84, 215-229. [CrossRef]

24. Chen, S.M.; Lee, L.W. Fuzzy Multiple Attributes Group Decision-Making Based on the Ranking Values and the Arithmetic Operations of Interval Type-2 Fuzzy Sets. Expert Syst. Appl. Int. J. 2010, 37, 824-833. [CrossRef]

25. Kumar, A.; Dash, M.K. Causal Modelling and Analysis Evaluation of Online Reputation Management Using Fuzzy Delphi and DEMATEL. Int. J. Strateg. Decis. Sci. 2017, 8, 27-45. [CrossRef]

26. Abdollahi, S.M.; Ranjbarian, B.; Kazemi, A. An Investigation of the Antecedents of Consumers' Confusion in Purchasing an Outbound Package Tour in the City of Isfahan by Fuzzy Delphi Method. Iran. J. Manag. Stud. 2020, 13, 527-564. [CrossRef]

27. Jani, N.M.; Zakaria, M.H.; Maksom, Z.; Haniff, M.S.M.; Mustapha, R. Validating Antecedents of Customer Engagement in Social Networking Sites Using Fuzzy Delphi Analysis. Int. J. Adv. Comput. Sci. Appl. 2018, 9, 294-304. [CrossRef]

28. Komatina, N.; Djapan, M.; Ristić, I.; Aleksić, A. Fulfilling External Stakeholders' Demands-Enhancement Workplace Safety Using Fuzzy MCDM. Sustainability 2021, 13, 2892. [CrossRef]

29. Garg, H. Generalised Pythagorean Fuzzy Geometric Interactive Aggregation Operators Using Einstein Operations and Their Application to Decision Making. J. Exp. Theor. Artif. Intell. 2018, 30, 763-794. [CrossRef]

30. Aminifar, S. Uncertainty Avoider Interval Type II Defuzzification Method. Math. Probl. Eng. 2020, 2020, 5812163. [CrossRef] 
31. Mahmoudi, S.; Ranjbarian, B.; Fathi, S. Factors Influencing on Iran's Image as a Tourism Destination. Int. J. Serv. Oper. Manag. 2017, 26, 186-210. [CrossRef]

32. Wang, Y.J. A Fuzzy Multi-Criteria Decision-Making Model Based on Simple Additive Weighting Method and Relative Preference Relation. Appl. Soft Comput. 2015, 30, 412-420. [CrossRef]

33. Orojloo, M.; Hashemy Shahdany, S.M.; Roozbahani, A. Developing an Integrated Risk Management Framework for Agricultural Water Conveyance and Distribution Systems within Fuzzy Decision Making Approaches. Sci. Total Environ. 2018, 627, 1363-1376. [CrossRef]

34. Kanuganti, S.; Agarwala, R.; Dutta, B.; Bhanegaonkar, P.N.; Singh, A.P.; Sarkar, A.K. Road Safety Analysis Using Multi Criteria Approach: A Case Study in India. Transp. Res. Procedia 2017, 25, 4649-4661. [CrossRef]

35. Muslihudin, M.; Susanti, T.S.; Maseleno, A.; Pringsewu, S. The Priority of Rural Road Development Using Fuzzy Logic Based Simple Additive Weighting. Int. J. Pure Appl. Math. 2018, 118, 9-16.

36. Kusumadewi, S. Fuzzy Multi-Attribute Decision Making (Fuzzy MADM); Graha Ilmu: Istimewa Yogyakarta, Indonesia, 2006.

37. Sagar, M.K.; Jayaswal, P.; Kushwah, K. Exploring Fuzzy SAW Method for Maintenance Strategy Selection Problem of Material Handling Equipment. Int. J. Curr. Eng. Technol. 2013, 3, 600-605.

38. Chou, C.C. The Canonical Representation of Multiplication Operation on Triangular Fuzzy Numbers. Comput. Math. Appl. 2003, 45, 1601-1610. [CrossRef]

39. Roszkowska, E.; Kacprzak, D. The Fuzzy Saw and Fuzzy TOPSIS Procedures Based on Ordered Fuzzy Numbers. Inf. Sci. Int. J. 2016, 369, 564-584. [CrossRef]

40. Shih, H.S.; Shyur, H.J.; Lee, E.S. An Extension of TOPSIS for Group Decision Making. Math. Comput. Model. 2007, 45, 801-813. [CrossRef]

41. Kahraman, C.; Öztayşi, B.; Uçal Sari, I.; Turanoğlu, E. Fuzzy Analytic Hierarchy Process with Interval Type-2 Fuzzy Sets. Knowl. Based Syst. 2014, 59, 48-57. [CrossRef]

42. Tiberius, V.; Hoffmeister, L.; Weyland, M. Prospective Shifts in Executive Education: An International Delphi Study. Int. J. Manag. Educ. 2021, 19, 100514. [CrossRef]

43. Silva, M.M.; de Gusmão, A.P.H.; Poleto, T.; Silva, L.C.E.; Costa, A.P.C.S. A Multidimensional Approach to Information Security Risk Management Using FMEA and Fuzzy Theory. Int. J. Inf. Manag. 2014, 34, 733-740. [CrossRef]

44. Liu, H.C.; Liu, L.; Liu, N.; Mao, L.X. Risk Evaluation in Failure Mode and Effects Analysis with Extended VIKOR Method under Fuzzy Environment. Expert Syst. Appl. Int. J. 2012, 39, 12926-12934. [CrossRef]

45. Wu, Y.J.; Chen, J.C. Stimulating Innovation with an Innovative Curriculum: A Curriculum Design for a Course on New Product Development. Int. J. Manag. Educ. 2021, 19, 100561. [CrossRef]

46. Zhang, H.; Zhang, W.; Mei, C. Entropy of Interval-Valued Fuzzy Sets Based on Distance and Its Relationship with Similarity Measure. Knowl. Based Syst. 2009, 22, 449-454. [CrossRef]

47. Xu, Z.S. A Ranking Arithmetic for Fuzzy Mutual Complementary Judgment Matrices. J. Syst. Eng. 2001, 16, 311-314. 